\title{
RAS Family Transcriptional Profile
}

National Cancer Institute

\section{Source}

National Cancer Institute. RAS Family Transcriptional Profile. NCI Thesaurus. Code C129761.

A data set that both identifies the RAS family proteins that are present and quantifies their concentration in a biological sample or specimen. 